\title{
Miguel de Cervantes
}

(edición de Juan Montero en colaboración con Francisco J.

Escobar y Flavia Gherardi)

La Galatea

Madrid, Real Academia Española, 2014, 783 p.

ISBN 978-84-672-6144-8 / 978-84-16072-90-3

\section{Daniel Fernández Rodríguez}

Universitat Autònoma de Barcelona

daniel.fernandez.tejerina@gmail.com

Pocos géneros han perdido tanto lustre y prestigio, lector y literario, como la novela pastoril. Arrumbada desde hace siglos en los desvanes de la filología, sobrevive a duras penas en la memoria de aulas y bibliotecas, y solo cuando algún abnegado estudioso le dedica sus afanes da señales de vida. Lo cual sucede de tiempo en tiempo y, por regla general, con ocasión de que cualquiera de los arriba mentados se aplique con todo el mimo y cuidado del mundo a sacar de nuevo a la luz alguna de sus obras más representativas. Y esa es justamente la labor que han llevado a cabo Juan Montero, Francisco J. Escobar y Flavia Gherardi con la edición de La Galatea de Miguel de Cervantes.

Aun siendo considerada como la menos genuinamente pastoril de las que se acogen a tal marbete ( $«$ La Galatea es la única novela pastoril que no aburre a las ovejas», según la boutade del poeta Jacobo Cortines con que los editores encabezan la presentación), pesan sobre ella sin embargo las desventajas del género, y ni siquiera en este caso el universal renombre del autor le sirve de atenuante. Máxime si se tiene en cuenta, como los editores se apresuran a señalar también en la presentación, que el propio Cervantes sembró algunas dudas sobre el crédito que le merecía su obra en el famoso episodio del escrutinio de la biblioteca de don Quijote: «... tiene algo de buena invención: propone algo, y no concluye nada; es menester esperar la segunda parte que promete» $(I, 6)$. Pero la segunda parte no llegó, por más que hasta sus últimos días le rondó a Cervantes la idea de escribirla.

El primer apartado del estudio introductorio está dedicado al proceso de redacción y otras cuestiones anejas. Que La primera parte de la Galatea dividida 
en seis libros saliera de las prensas alcalaínas de Juan Gracián en 1585 se explica porque fue en esa ciudad donde se gestó, al calor de un círculo de literatos que buscaron el amparo y mecenazgo del todopoderoso Mateo Vázquez de Leca, secretario del monarca Felipe II, y del eclesiástico y erudito italiano Ascanio Colonna, a quien finalmente dedicó Cervantes La Galatea. Se trata, como es sabido, de su primera obra, con la que el soldado de Lepanto y prisionero de Argel pretendía hacerse un hueco en el mundo de las letras. Si de todos los caminos que este mundo le brindaba eligió el pastoril, fue por dos razones: la primera, porque la novela de pastores estaba de moda desde la publicación en 1559 de La Diana de Montemayor; la segunda, por ser un género abierto que ofrecía múltiples posibilidades, como la de combinar la prosa y el verso o la de "yuxtaponer el fondo clasicista del bucolismo con la modernidad de las narraciones intercaladas" (p. 440).

Abordan a continuación los editores las claves estilísticas, formales y de contenido de la novela cervantina. Por lo que se refiere a las primeras, se destaca como rasgo fundamental la ya mencionada mezcla de prosa y verso, tras los pasos de Sannazaro en su Arcadia y de Jorge de Montemayor. El escritor portugués fue pionero además en la fórmula narrativa, de procedencia caballeresca, consistente en fusionar historias en principio independientes sin dejar por ello de enlazarlas con los insertos poéticos. Sobre este cañamazo, Cervantes se dispondrá a urdir con nuevos hilos la composición de su Galatea, con la vista puesta en «integrar la variedad episódica con la unidad, un esquema que a la postre será decisivo para la elaboración del mismísimo Quijote» (p. X).

Por de pronto, incrementa el componente lírico con respecto a lo que venía siendo norma y tradición: setenta y nueve poemas en total, cifra bastante superior a las de sus predecesores en el género pastoril. Además de responder a una situación psicológica y de resultar muy variada, la parte lírica confiere una clara impronta poética a la novela. Pero su función va más allá, por cuanto contribuye también a forjar la simetría estructural del relato, abriendo o cerrando los distintos episodios, marcando los cambios de escenarios y personajes, o modificando el enfoque narrativo. En ocasiones, los versos anticipan asimismo algún hecho, despertando la curiosidad del lector y de los propios personajes; en otras, resumen lo ya contado o sucedido, facilitando, por ejemplo, la anagnórisis, tan frecuente en este tipo de novelas. Todo lo cual lleva a la conclusión de que en el caso de $L a$ Galatea no puede hablarse de una subordinación de los versos a la prosa, pues son más bien aquellos y no esta los que encauzan el curso de la narración, al revés de lo que ocurría en las respectivas Dianas de Montemayor y Gil Polo.

Habida cuenta de su importancia en la obra —el propio autor se refiere a la redacción de La Galatea como «la ocupación de escrebir églogas»—, en su estudio los editores examinan con atención la parte poética, formada por nada menos que casi cinco mil versos en total. Aparte de lucir en ella sus dotes de buen versificador, Cervantes se atreve además a probar géneros, temas y metros variados, mostrando en esto último su preferencia por todo lo venido de Italia: tercetos, 
canciones en estancias a la manera petrarquista, octavas, sonetos, una canción en liras, una sextina, etc. La tradición octosilábica castellana está presente en las estrofas de tipo cancioneril, con predominio de las coplas reales y de las coplas castellanas. Un caso digno de mención es el Canto de Calíope del Libro VI (considerado por Alberto Blecua el estreno de Cervantes como «historiador de la literatura", labor que culminaría en 1614 con el Viaje al Parnaso), en el que se rinde homenaje a un centenar de poetas vivos españoles y del Nuevo Mundo.

En conjunto, la obra se mantiene fiel a los postulados estilísticos y retóricos consagrados desde la antigüedad y adoptados por la tradición (Virgilio, Petrarca, Sannazaro, Garcilaso, Montemayor o Gil Polo). Como un rasgo peculiar de la teoría literaria de la época en el tratamiento de la materia amorosa, cabe considerar «el nivelamiento de los pastores con los galanes cortesanos de otras tipologías narrativas» (p. 532). Sigue en ello Cervantes la «retórica petrarquizante» adoptada por la novela pastoril, que ha llevado a algunos críticos a plantearse el problema de que sus personajes se comportan en realidad como «discretos cortesanos", aunque aparezcan disfrazados de «rústicos pastores». El propio Cervantes debió de ser consciente de tal riesgo, y en el prólogo dirigido a los lectores se defiende de las posibles acusaciones por haber empleado un estilo demasiado elevado. Inspirándose en las anotaciones de Herrera sobre el género bucólico, en ese mismo prólogo fija además las normas expresivas por las que se ha de regir la literatura pastoril en lengua castellana, que ha de ser capaz de aunar «facilidad y dulzura», "gravedad y elocuencia». Precisamente el mayor logro de Cervantes en este terreno habría sido la consecución de una prosa que no desentona del verso con el que convive, así como de un estilo que es a la vez natural y artístico, además de vivo y variado.

Nuestro autor, amigo siempre de enmendarles la plana a sus modelos, ensayó también alguna novedad, principalmente en el modo de ensamblar la ficción pastoril y su espacio bucólico con los episodios intercalados, situados en ambientes más reales y variados. La principal, en palabras de Rey Hazas, consiste en «la apertura del pastorilismo hacia la realidad» (p. 455) mediante técnicas diversas: narración de su historia por parte de un personaje para satisfacer la curiosidad de sus oyentes, como hace Lisandro en la primera de las cuatro historias intercaladas; relato doble de un mismo hecho, desde perspectivas y puntos de vista complementarios, como el de Teolinda y su hermana Leonarda acerca de sus amores con Artidoro; interacción entre los diferentes personajes y niveles del desarrollo narrativo, etc. Todo un juego, en suma, de contrastes y paralelismos que conduce a la dinamización del espacio pastoril tradicional: los pastores no permanecen estáticos en las acostumbradas praderías y florestas sino que, en virtud del esquema de la peregrinatio, caminan y cuentan sus historias a la vez.

Por lo que respecta a la materia narrativa propiamente dicha, ocupa un lugar predominante la casuística amorosa, presente ya desde los mismos inicios de la obra, que arranca in medias res con los lamentos amorosos de Elicio y Erastro, pastores los dos de las riberas del Tajo y enamorados ambos de Galatea. Este triángulo amoroso no constituye sin embargo el principal hilo narrativo, limitándose 
su función a la de servir de relato-marco general, y aunque reaparece en diversas ocasiones a lo largo del libro y adquiere cierta relevancia hacia el final, ni siquiera llegamos a conocer su desenlace, aplazado por el autor para la Segunda parte que luego no escribió.

La misma casuística impregna las ya mencionadas cuatro historias que conforman la novela. En las tres primeras se recrean temas y situaciones de prolongada raigambre literaria: el amor trágico de Lisandro y Leonida, marcado por la rivalidad de sus respectivas familias, que incorpora unos ingredientes de violencia y odio completamente ajenos al bucólico universo pastoril, y cuyas fuentes remiten a las novelle de Matteo Bandello; el amor malogrado de Teolinda por culpa de una serie de equívocos derivados del extraordinario e inexplicable parecido físico entre dos parejas de hermanos, lo que permite al autor tratar un tema recurrente en el teatro y la novela del siglo XVI, el de los dobles, así como «integrar lo maravilloso en su obra sin tener que acudir a lo sobrenatural» (p. 472); el ejemplo de generosidad de Timbrio y Silerio, que, por mantener incólume su amistad, renuncian a Nísida, de la que los dos están enamorados, con raíces en el tema literario de «los dos amigos». También el amor juega un papel relevante en la cuarta historia, que queda inconclusa, y cuyo eje temático radica en «los conflictos derivados de la inexperiencia de unos jóvenes (Rosaura y Geraldo) que no saben cómo convertir su amor en matrimonio» (p. IX).

Las razones amorosas de los pastores llevan a las filosóficas sobre la misma materia en forma de disputas acerca de la naturaleza del amor, como la del libro IV, que viene a concluir en la existencia de tres distintas tipologías: el amor honesto, el útil y el deleitable. En este sentido, La Galatea, y la novela pastoril en general, pone de manifiesto la superación del neoplatonismo renacentista, que se va progresivamente cristianizando para adaptarse a la mentalidad contrarreformista, según explican los editores.

En el tercer apartado del estudio se informa cumplidamente sobre la historia del texto y los avatares que toda publicación conlleva en aquella época: los trámites administrativos de la edición, que se prolongaron durante catorce o quince meses, cuando habitualmente se resolvían en no más de ocho; la cesión de derechos por parte de Cervantes al librero alcalaíno Blas de Robles a cambio de 1.336 reales; o los pormenores de la impresión y composición, en las prensas de Juan Gracián, de la que sería la edición príncipe, puesta en circulación en marzo de 1585.

La acogida de la obra no fue tan favorable como Cervantes hubiera querido - y no alcanzó, desde luego, el éxito de las Dianas de Montemayor y Gil Polo-, si bien fue posteriormente reeditada en 1590 en Lisboa. Hubo que esperar a la aparición del Quijote en 1605 para que remontase el vuelo de la fama y fuese impresa en Francia en 1611, donde adquirió notable celebridad, según atestigua el licenciado Márquez Torres en su aprobación de la segunda parte del Quijote. Por ese mismo año de 1611 es posible que se hiciera en Baeza una nueva edición, aunque no existen pruebas concluyentes sobre la misma. Sí hay constancia fidedigna de que volvió a imprimirse en Valladolid en 1617, muerto ya el autor. De 
la edición vallisoletana derivó un año más tarde la que imprimió en Barcelona Sebastián de Cormellas, acaso en la misma imprenta que visitó don Quijote durante su estancia en la capital catalana. También en 1618 fue impresa en Lisboa, para adentrarse después, como todo el género pastoril, en la travesía del olvido.

Una travesía que duró algo más de un siglo, hasta 1736, año en que $L a$ Galatea tuvo el honor de ser reeditada en Madrid. Al calor de las nuevas modas del neoclasicismo galante y, sobre todo, de la creciente admiración por Cervantes en el siglo XviII, fue de nuevo reeditada en varias ocasiones, destacando particularmente la de Antonio Sancha en 1784, que sirvió de modelo para las que se hicieron en la primera mitad del xIx. Y así hasta llegar a la que publicó la editorial Rivadeneyra en 1846 dentro de las Obras de Cervantes que dan inicio a la Biblioteca de Autores Españoles.

Las ediciones anteriormente reseñadas se llevaron a cabo sin embargo desde el desconocimiento de la princeps, lastre al que vino a poner remedio la publicación de los doce volúmenes de las Obras completas de Cervantes que aparecieron entre 1863 y 1864 bajo los auspicios de Juan E. Hartzenbusch y Manuel Rivadeneyra. En el caso de La Galatea, la edición corrió a cargo de Cayetano Rosell, el primero en volver a tomar como texto base la princeps de 1585.

Otro hito en la peripecia editorial de La Galatea lo constituye sin duda la aparición en 1914 de la edición de Rodolfo Schevill y Adolfo Bonilla, que continúa siendo hasta hoy «la base para la vulgata del texto» (p. 558). A ella se han acogido los editores más recientes, como Juan Bautista de Avalle-Arce (1961 y 1987), Domingo Ynduráin (1993), Florencio Sevilla y Antonio Rey (1994 y 1996), Francisco López Estrada y María Teresa López García-Berdoy (1995).

En esa estela se inscribe también la presente edición para la Biblioteca Clásica de la Real Academia Española. En palabras de los autores, su principal objetivo es «ofrecer al lector un texto crítico de La Galatea que, partiendo de la princeps, renueve la actual vulgata del texto» (p. 560); anhelo holgadamente cumplido, merced al escrupuloso cotejo de la tradición textual de la obra, y al riguroso aparato crítico en el que no solo se da cuenta de las variantes correspondientes, sino que se proponen, comentan, despachan y aclaran otras tantas lecciones.

Como es de rigor en la colección a la que pertenece, de sobras conocida, el doble nivel de anotación solventará las necesidades de los distintos lectores que decidan acercarse a $L a$ Galatea. La riquísima información al alcance del público no solo atraerá a todos los interesados en la obra cervantina, sino que satisfará también la curiosidad y las dudas de investigadores y estudiosos. Los útiles índices de primeros versos, ingenios y notas facilitan el manejo de este clásico de la literatura española, que cuenta ahora con una edición crítica de lujo para cualquier paladar literario y filológico. 
